\title{
A TRANSITIVIDADE EM PALAVRAS E IMAGENS NO GÊNERO EDITORIAL
}

\author{
Maria Medianeira de Souza* \\ Francisco Roberto da Silva Santos*
}

\begin{abstract}
Resumo: A Linguística Sistêmico-Funcional (LSF) e a Multimodalidade Discursiva (MD) são nossas bases teóricas para investigarmos a transitividade verbal e visual, em editoriais das revistas Veja, Época, Uma e Todateen. Pesquisas em LSF e em MD comprovam que a transitividade, fenômeno que se estende para além do verbal, é relevante na configuração dos gêneros textuais. Com base nesse pressuposto, analisamos o papel que participantes do sistema de transitividade da LSF e participantes visuais da MD desempenham na construção do sentido do editorial. Os resultados ratificam a importância dessa categoria para a elaboração desse gênero e para a obtenção de seu propósito comunicativo.
\end{abstract}

Palavras-chave: Sintaxe. Transitividade. Gêneros textuais. Editorial.

\begin{abstract}
The Systemic-Functional Linguistics (SFL) and the Discursive Multimodality (DM) are the theoretical basis to investigate the verbal and visual transitivity, in editorials from the magazines Veja, Época, Uma and Todateen. Research in SFL and DM prove that the transitivity, phenomenon that extends beyond the verbal mode, is relevant in the configuration of textual genres. With that assumption, we analyze the role played by participants of transitivity system of SFL and visual participants of DM in the construction of the editorial meanings. Results ratify the importance of that category for the elaboration of that genre and for the achievement of its communicative purpose.
\end{abstract}

Keywords: Syntax. Transitivity. Textual genres. Editorial.

\section{Introdução}

Investigamos neste estudo o funcionamento da transitividade verbal e visual no gênero editorial porque compreendemos que refletir sobre a gramática, seja a do sistema da língua, seja a de uma gramática de imagens, como propõem Kress e van Leeuwen (2006), é refletir sobre significações e o processo de constituição destas significações encontradas nos mais diversos gêneros. Tanto a Linguística Sistêmico-Funcional (LSF), quanto a Gramática do Design Visual (GDV) comprovam que a transitividade tem grande relevância na constituição dos gêneros textuais. Além disso, podemos afirmar baseados em estudos anteriores (cf. SOUZA, 2006, 2011, FURTADO DA CUNHA; SOUZA, 2007), que no gênero editorial essa categoria linguística tem papel indiscutível.

O editorial tem como objetivo expressar uma opinião institucional e convencer o leitor a aderir a essa opinião, se constitui de modo que as experiências do mundo nele retratadas estejam a serviço da realização desse propósito. O editorialista é, então, um argumentador que organiza seu texto, com palavras e imagens, com o intuito de influenciar o seu leitor, conquistando-o, convencendo-o, fazendo-o agir ou pensar em uma determinada direção. Não podemos, no entanto, esquecer que, além do teor opinativo, os editoriais também são textos de apresentação dos conteúdos de um jornal ou de uma revista, ou podem, ainda, simultaneamente, opinar e apresentar o veículo no qual se insere. Com esse norte, analisamos vinte e quatro (24) editoriais das revistas Veja, Época, Uma e Todateen - visando a averiguar a contribuição da transitividade verbal e visual - investigando mais especificamente os processos materiais para a construção das opiniões ou apresentações veiculadas nesse gênero.

\footnotetext{
* Doutora em Letras pela Universidade Federal de Pernambuco (UFPE). Professora Adjunta III da Universidade Federal de Pernambuco (UFPE). Endereço eletrônico: medianeirasouza @ yahoo.com.br

* Mestre em Letras pela Universidade do Estado do Rio Grande do Norte (UERN). Professor Assistente I da Universidade do Estado do Rio Grande do Norte (UERN). Endereço eletrônico: frobertossantos @ hotmail.com
} 
O exame da transitividade visual, no escopo deste artigo, está exemplificada pela análise de um editorial da revista Todateen.

Como base teórica para a análise da transitividade da oração, recorremos à LSF (cf. HALLIDAY; MATTHIESSEN, 2004), e para análise da transitividade das imagens, utilizamos o aparato teórico-metodológico da GDV (cf. KRESS; van LEEUWEN, 1996, 2006). Esta última deriva-se da primeira e, portanto, é cara a ambas a compreensão da linguagem como um sistema semiótico social e um dos sistemas de significado que compõem a cultura humana.

A LSF institui que a linguagem, o texto e o contexto são responsáveis pela organização e desenvolvimento da experiência humana. Nessa teoria, estudam-se, então, as formas léxico-gramaticais, como a transitividade, em relação a suas funções sociais, sendo a transitividade entendida como um sistema e como a categoria gramatical referente à representação das ideias da experiência humana, isto é, experiências do mundo exterior e interior. Esse sistema permite identificar não só as ações e atividades humanas que estão sendo expressas no discurso, como também a realidade que está sendo retratada, já que é através da linguagem que falamos: de nossas experiências obtidas nas relações com as pessoas e objetos; das abstrações; e das qualidades, estados e relações existentes. A identificação dessas experiências codificadas nos textos se dá através dos principais papéis de transitividade: processos, participantes, e circunstâncias, os quais nos permitem analisar quem faz o quê, a quem e em que circunstâncias. A LSF estabelece seis tipos de processo do sistema de transitividade: materiais, relacionais, mentais, verbais, existenciais e comportamentais.

A multimodalidade, objeto de análise da GDV, é definida como a gama de recursos semióticos presentes em um gênero ou um evento discursivo. Complementando essa noção, afirma Dionísio (2005b, p. 178): "referimo-nos à multimodalidade discursiva como um traço constitutivo de todos os gêneros textuais escritos e orais. Consequentemente, recursos visuais e verbais precisam ser vistos como um todo, no processamento dos gêneros textuais". Os editoriais não fogem a essa regra, por isso, concordamos com Heberle (2004, p. 3), ao afirmar que "editoriais (...) são um exemplo do discurso multimodal, pois os elementos visuais e espaciais da página, com as diversas cores, o título em destaque, as fotos de pessoas sorrindo formam um significado social".

A pós-modernidade, com todos os seus avanços tecnológicos, principalmente nos meios de comunicação, possibilitou o surgimento de uma infinidade de gêneros emergentes gerados pelas novas relações sociointerativas que se estabeleceram. Além disso, os textos escritos passaram a empregar uma maior quantidade de elementos não-verbais em suas construções, inclusive os editoriais, especialmente os pertencentes às diversas revistas, entre elas as escolhidas para análise. Esse novo cenário demanda a necessidade de superarmos a crença de que as modalidades escrita e falada da língua são as únicas formas de representação de informação existentes e de se apoderar de mecanismos que nos permitam compreender esse uso de diversas semioses na composição dos gêneros. Além do mais, no bojo dessa compreensão, deve estar a premissa de que as estruturas visuais devem ser interpretadas, compreendendo-as como uma potencialidade de significados capazes de veicular sentidos ideológicos de acordo com os ideais da sociedade em que estão inseridas. Portanto, devem ser analisadas racionalmente de modo a considerar sua dimensão sócio-ideológica (cf. KRESS; van LEEUWEN, 1996, 2006).

Para atender a essas novas exigências, Kress e van Leeuwen (1996, 2006) configuram uma abordagem de estudos das imagens (elementos visuais diversos, incluindo o próprio texto numa página ou tela de computador) visando a dar conta dessa complexidade textual hoje predominante em todos os gêneros, em maior ou menor proporção. Tal abordagem, derivada dos princípios básicos de análise da LSF (cf. HALLIDAY; 
MATTHIESSEN, 2004), encontra-se na obra Reading Images: the Grammar of Visual Design (KRESS; van LEEUWEN, 1996, 2006), conhecida no Brasil como Gramática do Design Visual. Nesse estudo dos diversos sentidos materializados nas imagens e recursos semióticos diversos, os autores propõem uma análise dos elementos visuais, compreendendo as imagens como estruturas sintáticas que podem ser examinadas, assim como o são as estruturas sintáticas da linguagem verbal. Baseados na LSF, os referidos estudiosos postulam uma organização gramatical para o uso das imagens e tomam as categorias de base da LSF para moldarem sua proposta teórica. Essas categorias são, assim, reinterpretadas para atender às necessidades e objetivos desse modelo. As metafunções da linguagem da LSF: ideacional (expressão do conteúdo); interpessoal (expressão das interações sociais); e textual (estruturação do texto) são reformuladas como representacional (sintaxe da imagem: estruturas narrativas e estruturas conceptuais); interativa (relações particulares entre interlocutores e mundo: distância social, contato, ponto de vista e modalidade); e composicional (composição do texto: valor informativo, saliência e estruturação).

Em nossa análise, nos apoiaremos no sistema de transitividade da metafunção ideacional para a investigação da transitividade linguística, e nas estruturas narrativas da metafunção representacional para averiguação da transitividade da imagem, conforme sinteticamente apresentadas no tópico a seguir, as quais se fazem acompanhar dos exemplos ilustrativos da análise efetivada.

\section{A transitividade da oração}

Halliday (1985) define a linguagem como um sistema semiótico social e um dos sistemas de significado que compõem a cultura humana. Esse fato permite afirmar que a linguagem, o texto e o contexto, juntos, são responsáveis pela organização e desenvolvimento da experiência humana. Estudam-se, então, as formas léxico-gramaticais como a transitividade em relação a suas funções sociais. A transitividade é, então, entendida como a categoria gramatical, relacionada ao componente ideacional da Lingüística SistêmicoFuncional, referente à representação das ideias, da experiência humana (cf. HEBERLE, 1999), isto é, experiências do mundo real, inclusive do interior da consciência.

A transitividade é, portanto, a base da organização semântica da experiência e denota, não somente a familiar oposição entre verbos transitivos e intransitivos, mas um conjunto de tipos oracionais com diferentes transitividades. Conforme descrita na LSF, a transitividade possibilita identificar as ações e atividades humanas que estão sendo expressas no discurso e que realidade está sendo retratada. Essa identificação se dá através dos principais papéis de transitividade: processos, participantes, e circunstâncias e permite analisar quem faz o quê, a quem e em que circunstâncias. Cada tipo de processo - material, relacional, mental, verbal, comportamental e existencial - estabelece seu próprio esquema de construir um domínio particular da experiência. Dessa forma, o sistema de transitividade busca representar as experiências externas e internas que vivenciamos no mundo que nos rodeia e no mundo de nossa consciência, além de configurar também o mundo abstrato das relações de classificar e identificar (cf. HALLIDAY; MATTHIESSEN, 2004). Nessa construção dos conteúdos através do sistema de transitividade, portanto, três tipos de processo são tidos como principais: os materiais, os mentais e os relacionais; e três tidos como secundários: os comportamentais, os verbais e os existenciais.

Segundo Halliday e Matthiessen (2004), os processos secundários se encontram nas fronteiras entre os tipos principais, são processos intermediários, que guardam certas características do par que lhes cercam. Assim, olhando o sistema de transitividade, o qual representa nossa experiência, compreendemos que os diferentes processos formam um círculo, 
um espaço contínuo que contém o mundo físico, o mundo da consciência e o mundo das relações abstratas construindo a experiência humana (cf. HALLIDAY; MATTHIESSEN, 2004).

Orações com diferentes processos fazem contribuições distintivas para a construção da experiência nos vários domínios discursivos dos quais os gêneros são sua forma de expressão linguística. É certo que em certos fragmentos, ou mesmo em todo o texto, uma mistura de tipos de processos predomina, mas orações verbais têm lugar de destaque em notícias, e orações mentais são típicas da conversação casual. Já em textos narrativos, têm particular importância os processos existenciais e relacionais, mesmo que o plano principal seja construído predominantemente por processos materiais (cf. HALLIDAY; MATTHIESSEN, 2004).

Os processos materiais, objeto neste estudo, seguindo Halliday e Matthiessen (2004) são os mais acessíveis a nossa reflexão consciente e também os que na história da Linguística têm recebido mais atenção. São os materiais os responsáveis pela tradicional distinção verbos transitivos e intransitivos. As orações “... e as filas nos consultórios não param de crescer” e "Esses movimentos positivos na seara financeira ganharam velocidade na semana passada..." são descrições de processos materiais, cuja significação básica é a de que alguém ou algo faz alguma coisa. Nesse tipo de processo, o conceito de ação é subjacente. Ter uma ação presente envolve, pelo menos, um participante: o Ator, quando a oração é intransitiva, como no processo crescer; ou dois participantes, um Ator e uma Extensão, por exemplo, quando a oração é transitiva, como o exemplo com ganhar.

Nessa perspectiva, vejamos uma amostra da participação dos processos materiais nos editoriais analisados através dos processos fazer e chegar, respectivamente.

(1) Nesse aspecto, o governo pode exercer um papel decisivo, coisa que até agora ainda não conseguiu fazer. (VE8)

(2) ... a polícia atacava operários com cassetete e helicópteros faziam vôos rasantes. (EP3)

(3) O batom certo, uma pele bem cuidada, um bom creme para o rosto fazem milagres, pode apostar! (UM3)

(4) É por isso que a gente $f a z$ a todateen. (TT5)

Encontrado em todas as fontes, fazer tem no Houaiss Dicionário de Língua Portuguesa (2001), enquanto verbo transitivo, as acepções de criar, produzir, realizar, causar, obrigar, preparar, obter, atingir, haver (tempo decorrido), percorrer e estar (indicando temperatura). Nos nossos dados, encontramos a grande maioria das ocorrências desse processo com a acepção de realizar.

A oração do exemplo 1 localiza-se no argumento final do editorial e percebemos o tom de constatação de uma realidade e, ao mesmo tempo, de veredicto final, a opinião dada certa e definitiva pelo editorialista, caso em que a transitividade oracional, composta do processo material fazer, mais o participante Ator, o governo, materializa essa asserção. $\mathrm{Na}$ oração, "helicópteros faziam vôos rasantes", exemplo 2, temos uma ação complementando um quadro narrativo a respeito da postura do Presidente Lula, na comemoração de um $1^{\circ}$ de maio em ambiente hostil, antecipando o $1^{\circ}$ de maio de 2003, em que ele comemorara esse dia como presidente e chefe da segurança nacional. Esse quadro vai compor o painel geral de defesa de Lula, como um homem moderado, traçado e defendido em Época nesse editorial opinativo. Nas revistas femininas, embora fazer mantenha a mesma acepção dos outros exemplos, notamos diferenças em relação ao que tematizam e aos seus participantes. Não se trata de economia ou política, tampouco são participantes o governo, o mercado ou outros dessa 
natureza. Em virtude de seu público e de seu objetivo, outros participantes - creme, batom exemplo 3 - e a própria revista, exemplo 4, e uma outra configuração oracional entram em cena para buscar seduzir a mulher, adulta ou adolescente nesses editoriais.

Vejamos alguns exemplos com o processo material chegar:

(5) ... para que os países ricos e emergentes cheguem a um acordo em Cancún. (VE12)

(6) Uma quarta capa, mais genérica, chegará aos demais Estados. (EP12)

(7) Primavera chegando, visual novo! (UM5)

(8) Quando cheguei em casa, mal pude esperar para encontrá-lo de novo. (TT6)

Em (6), (7) e (8) temos orações das revistas Época, Uma e Todateen, cujos editoriais adotam a si mesmas como conteúdo, por isso, notarmos de antemão a não coincidência de participantes, comparando-as com o exemplo 5 que, por tratar do tema economia tem como Ator, o sintagma de cunho generalizante, os países ricos e emergentes, diferentemente dos participantes Atores dos exemplos que lhe seguem. Época refere-se ao fato de essa edição chegar às bancas com quatro capas diferentes; Uma traz o verbo chegar na última frase do editorial; é a conclusão do argumento anterior que incentiva leitoras a comprar, respaldada pela chegada da primavera. Nesse editorial de Todateen, a intergenericidade se faz presente e temos uma carta, na qual a revista "dá voz" a uma leitora, daí o uso inusitado, num editorial, da primeira pessoa do singular em (8), realizando uma ação, algo também pouco comum nesse gênero.

Há, nos dados, um predomínio das sentenças transitivas, através das quais podemos entender que a visão de mundo, a ser retratada nos editoriais, localiza-se na transição de uma força, no agir / fazer de alguém sobre um objeto ou um fato; é uma descrição de impactos que se expressa na língua pelas orações transitivas. Em virtude disso, orações que representam acontecimentos como as intransitivas tiveram baixa ocorrência nos dados.

No que diz respeito ao contexto mais imediato em que a oração se insere, observamos que isso provoca efeitos de sentido diferentes; não é que haja uma alteração de significado, há sim uma outra perspectiva significativa no que é veiculado por esses processos em função da teia argumentativa que vem sendo desenvolvida, o que faz da análise do sistema de transitividade em gêneros, como o editorial, uma atividade dinâmica e de crucial importância para a compreensão da gramática da língua como uma ferramenta criadora de sentidos.

\section{A estrutura narrativa: participantes e vetores}

Dentre os conceitos apresentados na Gramática Visual, damos ênfase aos processos narrativos, os quais são representados por participantes ligados por vetores que indicam ações. Para compreensão do conceito de estrutura narrativa é fundamental o entendimento dos conceitos de "Participantes" e de "Vetor" dentro da Gramática Visual. O termo "Participantes" é usado por Kress e van Leeuwen (2006, p.59) para referir-se a todos os objetos ou elementos que fazem parte de um processo visual relacionando-se uns com os outros; "Vetor" é o elemento que relaciona esses participantes. Na GDV, quando os participantes aparecem conectados por um Vetor, eles são representados como fazendo alguma coisa um ao outro, ou pelo outro. Nesses casos, a imagem representa uma estrutura 
narrativa ou processo narrativo, apresentando ações acarretadas e eventos, processos de mudança, arranjos espaciais, transitórios etc, portanto, estruturas transitivas.

Concebe-se que "diferentes tipos de processos narrativos podem ser diferenciados com base no tipo de vetor e no número e tipo de participantes envolvidos" (KRESS; van LEEUWEN, 2006, p. 63). Destacamos aqui o processo de ação e o processo de reação. $\mathrm{O}$ primeiro tipo relaciona dois participantes: o Ator, do qual o Vetor emana ou ele mesmo, inteiramente ou em parte, constitui o vetor; e a Meta, para a qual o Vetor é direcionado, aquela que "sofre" a ação. O processo reacional ocorre quando o Vetor é formado por uma linha que parte do olho de um participante chamado Reator em direção a um Fenômeno. $\mathrm{O}$ Reator deve necessariamente ser humano, ou um animal ou objeto personificado, que tenha olhos e expressão facial visíveis ao leitor. O Fenômeno, para o qual se dirige o olhar do Reator, pode ser formado por mais de um participante ou ser formado por uma estrutura narrativa. Observemos como essa transitividade visual pode realizar-se, tomando como ilustração o editorial da revista feminina Todateen: "É tempo de se apaixonar!", disposto a seguir (Fig. 1):

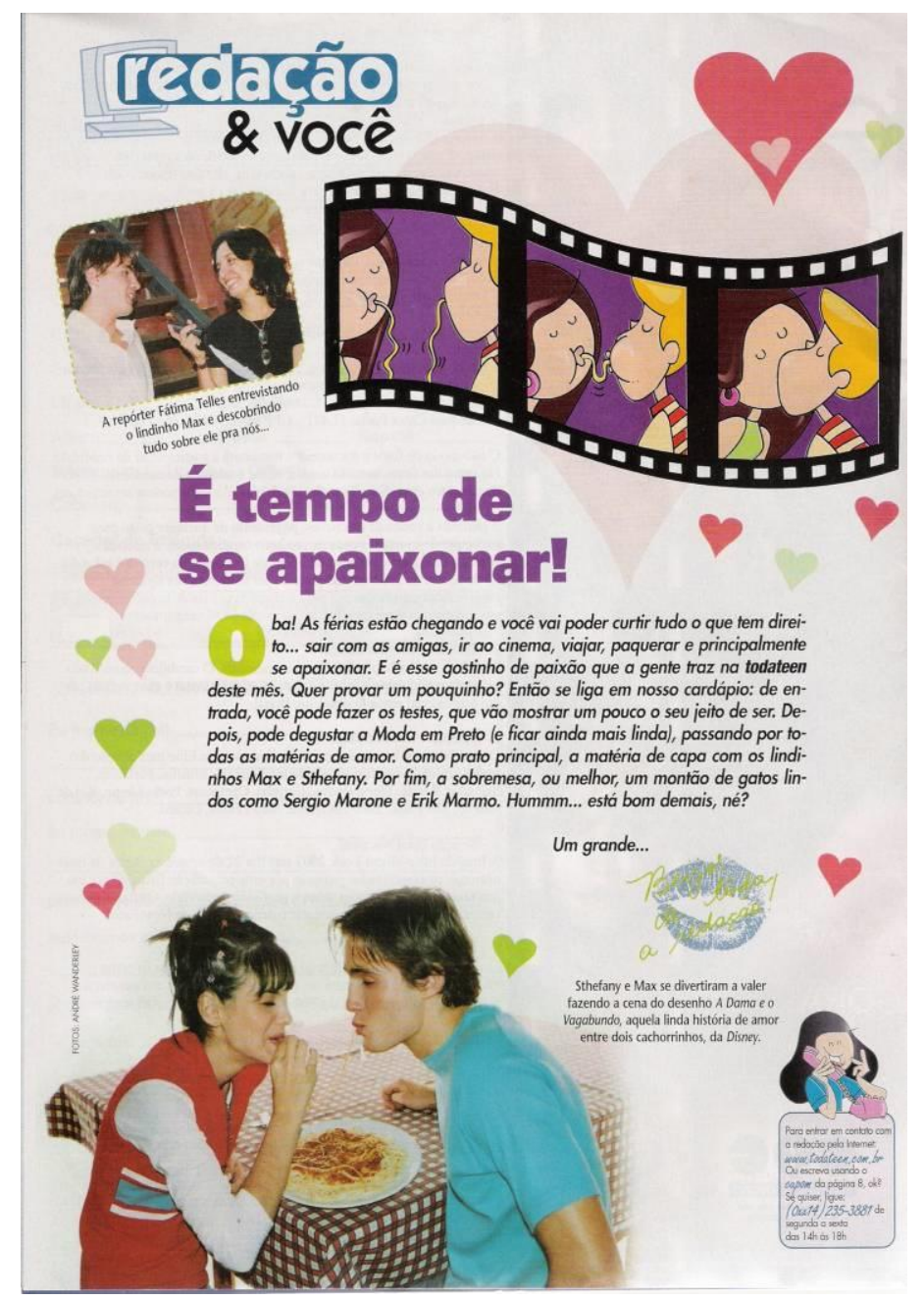

Figura 1 - Editorial de Todateen

Fonte: Revista Todateen, jul.2003.

A primeira fotografia, na parte superior esquerda apresenta uma estrutura narrativa transacional unidirecional, evidenciada pela presença de um vetor oblíquo, formado pela mão e o gravador da participante Fátima Telles, em direção ao participante Max, em que a repórter Fátima representa o participante Ator ao entrevistar o participante Max, que assume o papel 
de Meta. Ao mesmo tempo, temos um processo de reação bidirecional, notado pela presença de dois vetores formados pela linha do olhar do participante Max em direção à repórter Fátima, e vice-versa, sendo ambos, ao mesmo tempo, Reator e Fenômeno desse processo. Essa estrutura reforça o sentido de que ambos, repórter e entrevistado estão totalmente envolvidos na entrevista e comprometidos em perguntar e responder tudo aquilo que as leitoras de Todateen querem saber. Essa fotografia, pois, pretende evidenciar que a revista, como porta-voz do público, no caso representada pela imagem da repórter, realiza um trabalho ativo e eficaz de buscar as declarações e conhecer mais a fundo as celebridades teens cultuadas pelas leitoras. Esse sentido é confirmado pela legenda: "A repórter Fátima Telles entrevistando o lindinho Max e descobrindo tudo sobre ele para nós".

Em relação às outras imagens, vemos que há uma correspondência notável entre o desenho da parte superior direita da página e a fotografia na parte inferior. Temos uma película cinematográfica que mostra uma ação representada através de cenas estáticas. A primeira mostra um jovem casal comendo separadamente um prato de espaguete, na qual os jovens são os participantes Atores, cujo participante Meta, o espaguete, é simultaneamente o vetor representativo dos processos narrativos que se configuram no desenho. $\mathrm{Na}$ segunda cena, percebemos que os participantes Atores comem o mesmo espaguete; dividem, pois, a mesma Meta, o qual além de Meta é também Vetor da ação de comer, também se torna a ligação entre os dois jovens que vai acabar, na próxima cena da cadeia, juntando-os em um beijo apaixonado. Nesse desfecho, temos, então, outro tipo de processo: os jovens configuram-se como Interatores de um processo narrativo transacional bidirecional; isso quer dizer que cada participante assume, ao mesmo tempo, a função de Ator e de Meta do beijo recíproco. Essa série de cenas remete de imediato ao filme de animação A Dama e o Vagabundo, no qual um casal de cachorros divide um espaguete e também acabam beijandose calorosamente. A intertextualidade estabelecida demanda que as leitoras tragam à mente esse filme e façam essa leitura.

A fotografia da parte inferior, por sua vez, procura reproduzir o mesmo tipo de processo narrativo através de uma única cena estática. Nela, apesar da cena do beijo não chegar a se concretizar, a imagem permite, em conjunto com a memória do filme A Dama e $o$ Vagabundo, já evocado no desenho, antever que os participantes se beijarão quando o espaguete for totalmente consumido. Diferente do desenho, cujos participantes Atores não fazem parte do real, consistindo em caricaturas, representando, assim, de maneira genérica, qualquer casal apaixonado; a fotografia, por outro lado, retrata pessoas reais, representando a mesma cena. Mas o importante para a significação do editorial não é apenas a ação em si, mas as pessoas que a estão representando, ou seja, os famosos atores Sthefany e Max, idolatrados pelas jovens consumidoras da Todateen, naquele momento.

Conforme proposto por Kress e van Leeuwen (2006) e observado no exemplo analisado, também as imagens codificam ações e veiculam significações que, em harmonia e em integração com a modalidade escrita, constituem os propósitos comunicativos do gênero e consolidam práticas sociais complexas, por fazerem usos de diversas semioses, em diferentes contextos, como é o caso dos editoriais ora investigados. Com a análise da transitividade visual e em consonância com a LSF, na qual as escolhas linguísticas realizam significados, podemos comprovar que, como afirmam Kress e van Leeuwen, (1996, p.2), as "estruturas visuais realizam significados, assim como as estruturas lingüísticas, e, em conseqüência, destacam interpretações diferentes da experiência e diferentes formas de interação social".

\section{Considerações finais}


Os processos materiais encontrados em maior frequência nos dados comportam a possibilidade de se realizarem transitiva e intransitivamente. A predominância de sentenças transitivas envolvendo os processos materiais nos revela que as experiências de mundo retratadas nos editoriais são primordialmente dinâmicas, pois representam o agir, o fazer de algo ou alguém sobre um objeto ou um fato. Essa transição de força de algo ou alguém em direção a um objeto se mostra eficaz para a construção de uma realidade sobre a qual se quer moldar uma opinião. Nesse sentido, as orações transitivas encapsulando ações são mais impactantes do que as orações intransitivas que encapsulam acontecimentos, razão pela qual acreditamos que as sentenças intransitivas têm baixa ocorrência nos dados.

No que diz respeito aos diferentes contextos de usos, os processos materiais, como observamos nos editoriais de apresentação, podem também desempenhar funções descritivas, o que se coaduna com os pressupostos da LSF quando defende que todas as escolhas são significativas e que esses significados também são adquiridos na relação com outras escolhas. Essa diferença de papel dos processos materiais de acordo com o tipo de editorial é um dos traços que salientamos na composição do perfil desse gênero.

Queremos, por fim, destacar que editoriais diferentes e com conteúdos diversificados geram utilizações outras para um mesmo processo: em Veja e Época, a presença do editorial de apresentação faz com que essas revistas se tornem auto-referenciais, o que acarreta uma diferença nos significados expressos pelos processos e pelos participantes em relação aos jornais e às revistas femininas. Em Uma e Todateen, a mudança é mais evidente porque mais diversos são seus conteúdos e seus objetivos em relação aos outros editoriais investigados; assim, conteúdos e participantes dizem respeito a assuntos da esfera privada da mulher, e os participantes são, por vezes, individualizados no pronome "você", por exemplo, ou a mulher se torna autora de ações no texto através do pronome "nós".

As análises multimodais em diversos gêneros têm mostrado que a mera disposição gráfica constitui um recurso visual potencialmente forte a ponto de sermos capazes de identificar, por meio dele, um gênero escrito em língua estrangeira da qual não temos domínio (cf. DIONÍSIO, 2005). As imagens, por sua vez, comportam muitos aspectos significativos, uma vez que podem ter sua sintaxe analisada, como fizemos de forma exploratória neste estudo.

No editorial "É tempo de se apaixonar!" combinam-se fotografias, desenho, tira e escrita - no texto e na legenda - para tratar do tema do editorial; a paixão e uma de suas formas de expressão, o beijo. Observamos que o beijo, a ação de beijar, está presente na tira, na fotografia abaixo do texto e no desenho da despedida da equipe de redação. Também devemos ressaltar a dinamicidade das estruturas narrativas presentes nas imagens, tira e fotografia, com participantes Atores que intertextualmente reproduzem uma cena do filme $A$ dama e o vagabundo; a qual se espraia para outros recursos visuais, com participantes Atores, como na conversa ilustrada na fotografia no canto superior esquerdo e, com participante Dizente, no desenho da menininha ao telefone que simboliza o contato com a redação. Essa dinamicidade é reforçada pelos pequenos corações que se espalham pela página, pelo colorido do título da sessão e do editorial, e ainda pela letra inicial do texto. Juntos esses recursos compõem um quadro que exaltam a paixão e suas inquietantes manifestações, o que faz desse editorial um convite irresistível à sua leitura e de toda a revista.

A transitividade visual, portanto, é por demais saliente neste editorial e não levá-la em consideração em um estudo ou simples leitura desse gênero é não somente desprezar uma gama de significações por ela veiculada, como também reduzir à escrita a complexidade significativa que constitui o gênero editorial através da integração simbiótica entre os diversos recursos semióticos que o compõem.

\section{Referências}


BAZERMAN, C. The life of the genre, the life in the classroom. In: BISHOP, W.; H. OSTROM. Genre writing: issues arguments alternatives. Edwardsville: Southren Illinois University Press, 1997, p. 19-26.

BUTT, D. et. al. Using functional grammar: an explore's guide. Sydney: Macquarie University, 2001.

DIONÍSIO, Â. P.; MACHADO, A. R.; BEZERRA, M. A. (Orgs.). Gêneros textuais e ensino. Rio de Janeiro: Lucerna, 2002.

DIONISIO, A. P. 15 Anos de Superinteressante: uma análise visual das capas e manchetes. In: Investigações: lingüística e teoria literária. Vol.17, n. 2, julho 2004, Recife: Editora Universitária da UFPE, 2005, p. 179-192.

. Gêneros Multimodais e Multiletramento. In: Gêneros textuais: reflexões e ensino. A. M. KARWOSKI et. al. (Orgs). Palmas e União da Vitória, PR: Kaygangue, 2005, p.159-177.

Multimodalidade discursiva na atividade oral e escrita. In: Fala e Escrita. MARCUSCHI, L. A.; DIONISIO, A. P.. (Orgs). Belo Horizonte: Autêntica, 2005b, p.177-196.

EGGINS, S. An Introduction to Systemic Functional Linguistics. London: Pinter Publishers, 1995.

FURTADO DA CUNHA, M. A.; SOUZA, M. M. de. Transitividade e seus contextos de uso. Rio de Janeiro: Lucerna, 2007.

HALLIDAY, M. A. K. (). Notes on transitivity and theme in English. Journal of Linguistics, $\mathrm{n}^{\circ}$ 3, Part I, 1967a.

$1967 b$.

Notes on transitivity and theme in English. Journal of Linguistics, $\mathrm{n}^{\mathbf{0}}$ 3, Part II,

An Introduction to Functional Grammar. London: Edward Arnold, 1985.

HALLIDAY, M.A.K.; C. M. I. M. MATTHIESSEN. Introducion To Functional Grammar. 3. ed. London: Arnold, 2004

Systemic Funcional Grammar: A First Step Into the Theory. Disponível em: <http://web.uam.es/departamentos/filoyletras/filoinglesa/Courses/LFC-SFL/FirstStep.html> Acesso em 02 abril, 2016.

HERBELE, V. M. A representação das experiências femininas em editoriais de revistas para mulheres. Revista Iberoamericana de DISCURSO Y SOCIEDAD, v. 1 (3), p. 73-86. Barcelona: Editorial Gedisa, 1999.

An investigation of textual and parameters in editorials of women's magazines. Florianópolis/SC: UFSC, Programa de Pós-Graduação em Inglês e Literaturas Correspondentes, publicada no CD-ROM TELA (Tese do doutoramento), 1997. 
KRESS, G.; van LEEUWEN, T. Reading Images: The Grammar of Visual Design. London and New York: Routledge, 1996.

. Reading Images: The Grammar of Visual Design. London and New York: Routledge, 2006.

MARQUES DE MELO, J. Jornalismo opinativo: gêneros opinativos no jornalismo brasileiro. Campos do Jordão: Mantiqueira, 2003.

SOUZA, M. M. de. Transitividade e construção de sentido no gênero editorial. Recife/PE, 2006. Tese (Doutorado em Letras). Universidade Federal de Pernambuco.

Recebido em: abril de 2016.

Aprovado em: agosto de 2016. 